\title{
LA PUBLICIDAD O LA VENTA DEL IMAGINARIO OCULTO ¿EXISTE VIOLENCIA SEXISTA EN LOS ANUNCIOS?
}

Elvira Altés

elvira.altes@uab.cat Universitat Autònoma de Barcelona

Recibido: 22-11-2011

Aceptado: 28-02-2012

\section{Resumen}

La publicidad, mediante el uso persuasivo de imágenes y palabras, articula un discurso que refuerza y legitima las pautas de género de la sociedad patriarcal. La propuesta de modelos, normas y valores que perpetúan el sexismo, y que el discurso publicitario difunde a través de la violencia simbólica, contribuye a la configuración de las identidades, tanto femeninas como masculinas, convirtiéndose así en un dispositivo de consolidación e imposición de la desigualdad.

Palabras clave: Identidad, violencia simbólica, estereotipos.

\begin{abstract}
:
Advertising, through the persuasive use of images and words, articulates a discourse that strengths and legitimates the gender guidelines of the patriarchal society. The proposal of models, rules and values that perpetuates sexism, spread by the advertising discourse throught the symbolic violence, contributes to shape the identities, both feminine and masculine, converting itself in a device for the consolidation and imposition of the inequality.
\end{abstract}

Key words: Identity, symbolic violence, stereotypes. 


\section{Introducción}

"Aceptamos el sistema global de imágenes publicitarias como aceptamos el clima", dice John Berger (2000: 144), en Modos de ver. Y en el pecado tenemos la penitencia, porque al asistir sin inmutarnos al desfile de anuncios que nos acechan en todas partes quizá perdemos de vista las repercusiones que tiene el discurso publicitario en nuestra vida cotidiana.

Vivimos en perpetuo remojo en el caldo mediático, mantenemos un contacto diario, intenso y persistente con los medios de comunicación y cada vez más es a través de los medios que conocemos el mundo. Filtran y modelan las realidades cotidianas a través de sus representaciones singulares y múltiples y nos proporcionan referencias para nuestra vida diaria y para el mantenimiento del sentido común.

Los medios de comunicación nutren nuestro imaginario de material simbólico con el que construimos nuestra identidad. Y ¿qué características tiene ese material simbólico? En una considerable proporción reproducen la sociedad patriarcal, aunque también pueden contener imágenes y mensajes críticos que pueden actuar como contrapeso al discurso predominante. A través de todos estos imputs producimos una construcción conjunta de significado. Una característica de los medios es que siguen representando a las mujeres de forma bastante dicotómica, y aunque principalmente aparecen como subordinadas a los hombres, también podemos encontrar mujeres con poder, se las muestra como perversas pero también como víctimas, conviven imágenes de mujeres como objetos sexuales con las de mujeres cuidadoras. En cambio, a los hombres se les muestra en una variedad de roles, casi siempre positivos: se les ve poderosos, asertivos, resolutivos y sus necesidades y opiniones son tomadas en serio por los medios.

La publicidad incide en la elaboración de representaciones compartidas y si tenemos en cuenta que el género es un territorio de transformación social de primer orden tenemos cantada una interacción entre la publicidad y la asunción de roles.

El sistema publicitario genera un tipo de mensajes que ponen en evidencia los valores dominantes de cada época, las reglas de convivencia, los sueños comunes, los valores, etc., en un discurso en el que su poder se expresa en la capacidad de sugerir comportamientos y de proponer subidentidades. La publicidad promueve modelos a los que aspirar, que suscitan deseos de identificación a partir de estrategias de persuasión, de un lenguaje mítico, etc.

Por otra parte, a pesar de que las representaciones simbólicas siguen impregnadas de los mitos y presupuestos de la sociedad patriarcal, tanto las chicas como los chicos tienen asumido el discurso de la igualdad y el convencimiento de que no existen diferencias entre nacer hombre o nacer mujer. Creo que este es uno de los problemas con los que nos enfrentamos, ya que los y las jóvenes han bajado la guardia y estas imágenes y discursos les llegan sin que hayan desarrollado una actitud crítica para desactivarlos.

Antes de adentrarnos en el análisis de la publicidad, puede ser pertinente ojear algunos resultados del último monitoreo de medios GMMP 2010 (un proyecto internacional que analiza 
la información de un día cada cinco años). La presencia y la representación de mujeres y hombres en los medios sigue siendo muy desigual, por ejemplo, las mujeres protagonizan el $27 \%$ de noticias, mientras los hombres, el $73 \%$. Se identifica a las mujeres por su parentesco con un hombre en el $17 \%$ de los casos, mientras que esta circunstancia se menciona en el $5 \%$ de las veces para los hombres. La función en la que aparecen más mujeres es en la de la opinión popular, en cambio, para la opinión experta los medios consultan al 91\% de hombres y solo al $9 \%$ de mujeres. Se ha llegado a la conclusión que el relato del $80 \%$ de noticias refuerza los estereotipos, mientras sólo el $6 \%$ los cuestionan. Estos datos mantienen algunos paralelismos con la publicidad, actuando como dispositivos que se retroalimentan.

\section{El concepto violencia y sus manifestaciones en los medios}

Desde la perspectiva tradicional, un acto de violencia es cuando alguien hace algo sobre otra persona con la intención de causar unos efectos. Así, en esta definición se contempla la intencionalidad del sujeto que causa violencia como factor clave, pero ¿qué sucede con la violencia que nos llega de los medios de comunicación? Según José Sanmartín (2000), la importancia de los medios no reside en su calidad de inductores directos, sino en su capacidad de facilitar ideas y procedimientos para llevarlas a cabo.

Hay multitud de estudios que intentan explicar en qué medida la violencia que transmiten los medios induce a los individuos a ejercerla (Garrido Lora, 2004; CECU, 2003; Fernández Morales, 2008 o Cuadrado Zurinaga, 2001). El estudio más importante llevado a cabo hasta ahora es el norteamericano National Television Violence Study, en cuyas conclusiones avisa que la violencia en televisión produce tres tipos de efectos: 1) interviene en el aprendizaje de actitudes y conductas agresivas; 2) insensibiliza frente a la violencia y 3) incrementa el miedo a ser víctima de la violencia.

Este estudio, después de analizar durante tres temporadas la programación de la televisión, encuentra que el $57 \%$ de los programas conlleva alguna muestra de violencia, aparecen 8.000 escenas violentas y 18.000 interacciones violentas. Sólo el $4 \%$ del total plantea una clara filosofía antiviolencia. Presenta dos conclusiones: la presencia de la violencia en la televisión es muy alta y la forma como se representa no permite reducir o inhibir el aprendizaje de la violencia.

Dos constataciones personales que surgen de la mera observación: los medios difunden mucha más violencia que la que cualquier individuo puede vivir como experiencia personal, y segunda, en nuestra sociedad, los medios gestionan el miedo y la adrenalina.

En otro estudio, este realizado por Manuel Garrido Lara (2004) sobre 1068 spots publicitarios emitidos por cadenas españolas, se ha hallado que en el 53,57\% de los casos la representación de la violencia en los spots suele ser física, directa, sin provocación previa, sin consecuencias visibles, y edulcorada con humor. El trabajo concluye que resulta perniciosa para el aprendizaje de pautas de comportamiento 


\section{La violencia simbólica}

En los últimos años se pueden observar cambios substanciales en la representación de la violencia contra las mujeres, ya no se muestra de forma explícita, ahora la violencia que se detecta es de tipo simbólico. Se trata de un dispositivo que consigue naturalizar la desigualdad a partir de las diferencias. Los medios en general y la publicidad en concreto son excelentes aliados en el manejo de las formas retóricas para transmitir los valores asociados al patriarcado.

La publicidad de prostitución en la prensa y también en la televisión es, además de una afrenta para los conceptos de igualdad y de dignidad, una muestra clara de violencia simbólica que ha empezado a cambiar. La fuerza simbólica es una forma de poder que se ejerce directamente sobre los cuerpos y, como por arte de magia, sin ningún tipo de coacción. Cuando el grupo hegemónico consigue que el grupo dominado integre sus esquemas, valores e interpretaciones culturales se ha completado el proceso de la violencia simbólica.

La lógica paradójica de la dominación masculina y de la sumisión femenina solo se entiende por los efectos duraderos que el orden social ejerce sobre las mujeres y los hombres. "Cuando el grupo dominado aplica a lo que le domina unos esquemas que son el producto de la dominación o, cuando sus pensamientos y sus percepciones están estructurados de acuerdo con las propias estructuras de la relación de dominación que se les ha impuesto, sus actos de conocimiento son inevitablemente actos de reconocimiento, de sumisión" (Bourdieu, 1999:26).

En la publicidad, las prescripciones de género se perpetúan mediante la seducción que transmiten los estereotipos. Sabemos que el mandato de género es la construcción cultural que consagra la desigualdad y la desventaja económica, social, política y cultural de las mujeres respecto a los hombres, y lo consigue con la complicidad de los medios, que ejercen una función transmisora de los valores, normas y comportamientos que cada momento histórico asigna a la feminidad y a la masculinidad.

\section{La audiencia en su interacción con los medios}

Según Rodrigo Alsina (1998), los públicos responden a un contrato pragmático que le propone quien produce el discurso, que es quien sabe la forma adecuada de interpretarlo.

En los informativos, el contrato es hacer saber, en el entretenimiento se quiere hacer sentir y en la publicidad se establece un contrato pragmático manipulador, ya que pretende hacer algo a las personas destinatarias.

En la actualidad se produce una mezcla de géneros, sobre todo en la televisión, que genera incertidumbre en el público receptor respecto al contrato social que se establece con los medios. Los límites de la publicidad se han ido difuminando en nuestro espacio cotidiano, que se ha ido volviendo más complejo. La publicidad funciona como un género comunicativo que actúa transversalmente en relación a otras prácticas, como programas, series, eventos sociales, en la promoción de valores y conductas responsables. 
La audiencia es capaz de descodificar mensajes muy complejos pero no por ello es competente en la captación de contenidos sexistas y discriminatorios y en la percepción del significado que la publicidad contemporánea trae consigo. iertamente, los públicos son cada vez más conscientes de que la publicidad es un tipo de comunicación persuasiva con una finalidad explícita, saben que es un mensaje ilusorio, que apela al deseo y que busca promover el consumo, pero eso no significa que no siga siendo eficaz.

La publicidad ha sabido adaptarse y generar nuevos contextos comunicativos. Actualmente se habla de comunidad de marca, se pretende que la audiencia adopte una actitud interactiva que facilite la identificación con el estilo de vida que promueve la marca. El imaginario y los valores no se imponen a la audiencia: se le propone que los asimilen. Con la idea de que son algo construido colectivamente, se estimula la participación de la audiencia a través de Youtube, con la parodia de anuncios, propuestas de interpretación distintas, concursos, etc.

\section{5. ¿Cómo funciona la publicidad?}

Debemos recordar que la publicidad moderna nace con el periodismo, como un soporte económico para el medio. Después de un recorrido de más de dos siglos se le ha dado la vuelta a la idea, ahora podemos decir que los medios son anuncios publicitarios que llevan consigo información y entretenimiento, y cuyo cometido ha de ser la captación de público para sus anunciantes.

Es un clásico hacer la distinción entre propaganda y publicidad, situando la ideología del lado de la propaganda y el interés comercial del de la publicidad, pero les invito a revisar conmigo los conceptos que maneja la publicidad y les sugiero que no contengan su imaginación ni la circunscriban absolutamente a la función comercial:

Target es el público a quien va destinado el producto (que se detecta mediante una investigación de mercado).

Posicionar es diferenciarse de otros productos.

Segmentar es dirigirse al público objetivo o target.

Marca es la necesidad de dar nombre al producto, asignarle un logotipo i posicionarlo, que es la incitación a identificarlo con determinados valores (no olvidemos que construimos nuestra identidad por comparación, posición u oposición).

Segmentación la marca permite diferenciar el producto de otro de la competencia, pero para ello hay que adjudicarle unas características.

Valorización la clientela debe asociar la marca a una cualidad de la que los otros carecen y así justificar el precio y la adquisición. 
Probablemente estos conceptos permitirían intercambiar una marca con un candidato político, por ejemplo. Y no sólo porque la política se ha comercializado, sino porque en su origen también la publicidad comercial posee un fuerte contenido ideológico, aunque éste permanezca oculto.

El consumo es una de las utopías contemporáneas por excelencia y la publicidad es el adalid del capitalismo, refuerza los valores patriarcales, asegura la continuidad del status quo y aunque los anuncios parecen dirigirse de forma igualitaria a todo el mercado, lo cierto es que las personas no son iguales ante el mercado (ni en capacidad económica, ni en discernimiento crítico, etc.).

¿En qué momento del proceso de construcción de un mensaje publicitario se introduce el sesgo machista? En la segmentación, cuando se define el target o público objetivo es cuando se tienen en cuenta las subjetividades personales y ahí se introducen los estereotipos, los tópicos y aquellas definiciones consensuadas por la cosmovisión social del momento.

En la elaboración del relato publicitario se tiene en cuenta la nostalgia del paraíso que los humanos sentimos a menudo. De ahí que esas historias nos sitúan en un mundo feliz en el que una mujer no es una persona, sino que incorpora un paradigma de significados, connotaciones y contextualizaciones implícitas, de forma que el rol que encarna responde más a nuestro deseo que a la realidad. Gracias a la cosmovisión compartida, los estereotipos se muestran sutilmente en las suposiciones de partida acerca de lo que quiere una mujer y lo que quiere un hombre.

Por otra parte, para conseguir la reducción de la imagen femenina a tipologías esquemáticas como la bella, la perversa o la sumisa se emplean tres estrategias: el descrédito, el aislamiento i el socavamiento. Para desacreditar, destaca los aspectos negativos de la feminidad. Por ejemplo, es una mujer liberada, pero fría con los hombres; preocupada por la estética, pero superficial. Para aislarla se la coloca en un rol estático, la cocina, la compra, la cama, etc., y para socavar se la muestra como objeto o sujeto pasivo a disposición del hombre. Esta es a veces la forma más sutil, ya que de tan habitual pasa desapercibida.

Una estrategia de descrédito tiene que ver con las funciones fisiológicas y las mujeres: la publicidad muestra la parte vergonzosa de unos cuerpos imperfectos, que se hinchan, desprenden gases, producen almorranas, estreñimiento, pérdidas de orina, menstrúan, respondiendo así a un modelo de representación del cuerpo femenino que recuerda los tabús sociales.

El aislamiento se traduce a menudo en esa mujer preocupada por su aspecto, aunque se ha producido una cierta novedad, el estándar de belleza se ha desplazado (tras las fronteras de lo políticamente correcto) a los discursos del cuidado y de la buena salud del cuerpo. La idea es más compleja: el cuidado estético clásico se transforma en la retórica del cuidado y la salud, reforzando la noción de labor y esfuerzo. Naomi Wolf (1992) habla del "tercer turno laboral", como la obligación de la mujer de trabajar su cuerpo para conseguir la perfección.

La publicidad produce las representaciones devolviendo de forma estilizada lo que sucede en nuestra vida cotidiana: los personajes están ubicados en un escenario y en una 
relación socialmente definida y marcada entre otras cosas por el género. A partir de la circularidad y reflexividad de las representaciones culturales, se puede plantear el problema de la transmisión de los estereotipos sexistas.

En el estudio de 2008 Tratamiento de la variable género en la publicidad que se emite en los medios de titularidad pública (Rodríguez, Saiz y Velasco, 2009) a cargo de Red2Red Consultores para el Instituto de la Mujer, se analizaron 434 spots. Mientras la representación de hombres y mujeres es bastante equitativa 52\% hombres y $48 \%$ mujeres, aparecen muy claramente diferenciadas las designaciones de género, según el rol y el escenario que muestra el anuncio.

La voz en off de los anuncios se distribuye así: 106 femenina y 264 masculina, y según el tono de voz, las mujeres suelen aparecer en un registro amistoso y coloquial (46\%), y los hombres emplean un tono informativo y distante $(75 \%)$.

Mientras las mujeres actúan en el rol de madre en el 13,5\% de los spots, en el rol de padre encontramos el 3,1\%, en el papel de hija, un 3,5\% y el doble en el de hijo, el $7 \%$. Como consumidora, hallamos el $41 \%$ de mujeres y en el papel de consumidor, son casi la mitad, el $22 \%$, como experto, el $13 \%$ y como experta, un exiguo $1,4 \%$ (datos que se corresponden con el GMMP (2010)

Según la actividad, las mujeres que trabajan, son el 10,8\% y los hombres, el 25,6\%. En el capítulo de la diversión también se expresan diferencias, ya que las mujeres se divierten en un $10,8 \%$ y los hombres, más del doble, el 22,6\%. En cambio, cuidarse se sitúa del lado femenino, ya que las mujeres lo practican en un $27,3 \%$ y los hombres en un $8,3 \%$, igual que atender a otros que también cae del lado de las tareas femeninas, ya que se presentan un 12,9\% de mujeres en esa actividad y solo un $3 \%$ de individuos masculinos, los cuales se representan mostrando afecto en un $0,8 \%$ mientras se muestra a las mujeres en un 2,9\% en esta situación

En cuanto a los espacios/escenarios en los que se desarrolla la acción, hallamos a las mujeres como reinas del ámbito privado (60,5\%) y a los hombres se les encuentra en el 37,5\%. La casa y su entorno también son territorio femenino, ya que lo ocupan en el $41 \%$ de los casos, y los hombres en el 19\%, porcentajes que se invierten cuando el espacio al que se refiere es público, ahí encontramos el 28,2\% de mujeres y casi el doble de hombres (51\%). Los hombres aparecen el doble que las mujeres en el ámbito laboral, ellos el 20,5\% y ellas el 10,9\%

\section{El sexismo publicitario}

La publicidad es un territorio de textos, lemas, imágenes e historias donde tienen cabida diversas manifestaciones, desde las actitudes más sexistas, a los rasgos de sexismo camuflado, a la propia autocrítica: unos ejemplos y otros dialogan entre sí. Pero ¿podemos seguir hablando de sexismo publicitario? 
Se han producido algunos cambios en los discursos publicitarios, ha desaparecido o está en vías de extinción la maruja, los cuerpos fragmentados, estáticos e infantilizados, la competencia para lavar más blanco o hacer mejor café...

El sexismo que pervive en los anuncios es más la consecuencia de la reiteración de espacios estereotipados y de la atribución de funciones tradicionales a cada género que de estrategias discursivas concretas. Podemos rastrear el sexismo en los nuevos discursos:

- La pauta de belleza como un ideal que puede alcanzarse mediante transformaciones radicales, aplicación de productos o trucos,

- El cuerpo de las mujeres como un compendio de características negativas al que hay que disciplinar,

- Los hombres como ejemplos de sujeto genérico y de ciudadano,

- La voz masculina como criterio de autoridad y legitimidad,

- La asociación de la aventura, la libertad y la transgresión de las normas como territorios masculinos.

En la actualidad, la publicidad ya no recurre a estrategias sexistas tan evidentes como en épocas pasadas, la utilización de mujeres como objetos claramente denigrantes está en retroceso; ahora todo es mucho más evanescente, sutil, casi inapreciable, si no se desarrolla un sentido crítico que permita detectar aquellos anuncios que puedan ser calificados de sexistas. Porque el sexismo no ha desaparecido, sino que ha aprendido a camuflarse y opera en la reproducción de roles no igualitarios, se encubre con la máscara del humor, de la ironía, los dibujos o los gráficos, fórmulas que en un primer momento parecen rompedoras, pero que tras una mirada más atenta descubrimos que la patita que se nos muestra por debajo de la puerta es la de los estereotipos de toda la vida. Por tanto, el sexismo y la violencia se practica a través de la reiteración de roles y escenarios que se asocian a los valores tradicionales.

Por otra parte, los distintos géneros de los medios, la información, el entretenimiento y la publicidad se asocian y retroalimentan presentado un discurso similar. Es la lluvia fina que va calando, la mujer como personaje secundario, el que da la opinión popular en los informativos y el que cuenta su experiencia en el entretenimiento y la publicidad, mientras el rol principal se reserva al experto masculino que es quien detenta el saber.

\section{Conclusión}

La construcción social e individual de la identidad viene condicionada por la cosmovisión social y por el refuerzo mediático de los roles tradicionales de la feminidad y la masculinidad. A través de la violencia simbólica se produce el establecimiento y la naturalización de las pautas de género. Paralelamente, los medios tienden a la espectacularización y difusión de la violencia y contribuyen a la interiorización de los modelos 
de feminidad y masculinidad hegemónicos, determinando aquellos comportamientos que son propios y adecuados para cada género.

Sin embargo, la publicidad posee una doble dimensión, dos dinámicas que se producen simultáneamente: refuerzo e innovación. Refuerza las representaciones establecidas socialmente, como los estereotipos y, por otra parte, promueve el desplazamiento de estas, su cuestionamiento y la inserción de otras representaciones desconocidas o minoritarias; permite realizar lecturas distintas, según sus contextos vitales (edad, formación, clase social, etc.) por tanto, no se puede hablar de influencia unidireccional. Aunque existan ejes predominantes, no puede considerarse un discurso homogéneo, ya que hay espacio para lecturas múltiples. Por ejemplo, en 2009 el Observatorio de la imagen de las mujeres del Instituto de la Mujer recibió 360 quejas, y en 2010, 2.440, de las cuales un 13\% las habían formulado hombres.

Entonces ¿por qué resultan tan persistentes los estereotipos de género? No debemos olvidar que la sentimentalidad a la que apela la publicidad nos propone pasiones de acuerdo a cánones desiguales y aunque la razón nos permita problematizar las normas discriminatorias, los hábitos inconscientes y la naturalización de las normas de género convierten en tarea ardua el cambio personal y social de las mentalidades.

\section{BIBLIOGRAFÍA}

- Bourdieu, Pierre (2000): La dominación masculina. Barcelona: Anagrama.

- Garrido Lora, Manuel (2004): Violencia, televisión y publicidad: análisis narrativo de los estereotipos publicitarios de contenido violento. Ediciones Alfar: Sevilla.

- CECU - Acurema (2003): La mujer y la publicidad. Madrid: Dirección General de la Mujer, Consejería de Trabajo, Comunidad de Madrid.

- Fernández Morales, Marta (ed.) (2008): Publicidad y violencia de género: Un estudio multidisciplinar. Palma de Mallorca: Edicions UIB.

- Berger, John (2000): Modos der ver. Barcelona: Gustavo Gili.

- Cuadrado Zurinaga, Maika (2001): El género femenino a través de la publicidad. Madrid: Federación Mujeres Jóvenes.

- GMMP Proyecto de Monitoreo de Medios (2010): “Quien figura en las noticias?”. Coordinación para España: Elvira Altés, [en línea], disponible en: http://www.whomakesthenews.org/ [Aceso 13/12/2011].

- Rodríguez Gómez, Paz; Saiz Echezarreta, Vanesa y Velasco Gisbert, María Luisa (2009): Tratamiento de la variable género en la publicidad que se emite en los medios de titularidad pública. Instituto de la Mujer: Madrid. 